\title{
Corpus
}

Archivos virtuales de la alteridad americana

Vol 3, No 2 | 2013

Julio / Diciembre 2013

\section{Reflexiones de los autores sobre el Dossier}

Roberto Di Stefano, Miranda Lida, Alejandro Frigerio, Gustavo Andrés Ludueña, César Ceriani Cernadas, Pablo Semán y Verónica Giménez Béliveau

\section{OpenEdition}

\section{Journals}

Edición electrónica

URL: http://journals.openedition.org/corpusarchivos/617

DOI: 10.4000/corpusarchivos.617

ISSN: 1853-8037

Editor

Diego Escolar

\section{Referencia electrónica}

Roberto Di Stefano, Miranda Lida, Alejandro Frigerio, Gustavo Andrés Ludueña, César Ceriani

Cernadas, Pablo Semán y Verónica Giménez Béliveau, "Reflexiones de los autores sobre el Dossier », Corpus [En línea], Vol 3, No 2 | 2013, Publicado el 20 diciembre 2013, consultado el 06 mayo 2019.

URL : http://journals.openedition.org/corpusarchivos/617 ; DOI : 10.4000/corpusarchivos.617

Este documento fue generado automáticamente el 6 mayo 2019.

Licencia Creative Commons: Atribución-NoComercial 2.5 Argentina (CC BY-NC 2.5 AR) 


\title{
Reflexiones de los autores sobre el Dossier
}

\author{
Roberto Di Stefano, Miranda Lida, Alejandro Frigerio, Gustavo Andrés \\ Ludueña, César Ceriani Cernadas, Pablo Semán y Verónica Giménez \\ Béliveau
}

\section{Roberto Di Stefano}

1 ¿Cuándo hubo un "monopolio" católico? Si con el término se quiere indicar homogeneidad de creencias y prácticas, me atrevo a afirmar que nunca. Si en época colonial regía en la vida colectiva un régimen jurídico que buscaba garantizar la unanimidad -que es el segundo sentido que se me ocurre puede atribuirse a esa noción-, tenemos indicios suficientes para pensar que la realidad distaba mucho del ideal perseguido. Si lo contrario al monopolio es la diversidad, advierto a los amigos sociólogos y antropólogos que lo que ven en la actualidad es menos novedoso de lo que creen. Desde luego la configuración religiosa de la sociedad argentina a comienzos del siglo XXI es incomparable en muchos sentidos a la de los siglos XVIII y XIX, pero no precisamente en ése. Tendríamos que definir, en principio, qué entendemos por diferente-de lo católico. Si hoy consideramos que aunque la abrumadora mayoría de los argentinos se declara católica en las encuestas el dato es engañoso porque esconde religiosidades o espiritualidades autoconstruidas, no me parece que en el siglo XVIII las cosas fueran muy diferentes. Ya lo dije: ni los curas de las parroquias urbanas de Buenos Aires lograban que sus feligreses cumplieran con el precepto anual en el siglo XVIII. Si leemos los informes de los curas de otras áreas, sobre todo de las rurales, vamos a encontrarnos con situaciones parecidas.

2 La idea de que los argentinos eran católicos y que lo contrario constituía una anomalía, pervivió al desmantelamiento de ese régimen de unanimidad. Por ejemplo, hasta bien entrado el siglo XIX se consideraba a los argentinos como católicos y a los protestantes como extranjeros. Pero esa homologación no refleja ninguna unanimidad de creencias, 
sino que responde al hecho de que la adscripción religiosa tenía implicancias políticas y jurídicas. Mientras ese supuesto pervivía en los papeles y en los discursos, el ensanchamiento de los márgenes para expresar la disidencia permitía la visibilidad de las rebeldías, al tiempo que las nuevas condiciones sociales y culturales permitían el contacto con otras tradiciones religiosas. No faltan ejemplos tempranos de rechazo explícito de la religión heredada. Me parece significativa al respecto la actitud de individuos que ante la situación límite de la muerte se vieron libres de toda convención y de toda coerción, como los de los condenados a la pena capital -evocados en las memorias de guerreros de la independencia y de las contiendas civiles- que rehusaron los últimos auxilios antes de enfrentarse al pelotón de fusilamiento.

3 La pregunta del millón es cuán extraordinarios y excepcionales son esos casos, pero nunca la podremos responder, porque los historiadores del siglo XIX trabajamos con muertos. Podemos decir, como parte de una respuesta, que el catolicismo no parece haberse debilitado significativamente a lo largo del siglo, si es que la asistencia a los ritos y el apego a ciertas prácticas devocionales y sacramentales pueden considerarse datos significativos. Contrayéndome a Buenos Aires, que es el ámbito que mejor conozco, puedo señalar que son multitud los testimonios que dan cuenta de la vitalidad de las prácticas católicas: aun en la segunda mitad de la centuria, que se supone más "secularizada" que la primera, la prensa habla de templos llenos en las misas dominicales y de verdaderas multitudes en las grandes celebraciones de Pascua, Navidad o Corpus. Esa percepción parece confirmada por el hecho de que las parroquias urbanas ofrecían de cuatro o cinco misas diarias, sin contar las que se celebraban en cumplimiento de mandas de capellanías y de otras obras pías. A la misa más temprana, que se celebraba en invierno antes del alba, solían concurrir hombres y mujeres de trabajo que no podían escucharla durante la jornada laboral. En el ámbito rural, incluso en zonas donde la presencia del clero era rara, la religión solía practicarse en los hogares como mejor se podía. En el ocaso impiadoso de su vida, el anciano Eduardo Holmberg recordaba que su madre, presidiendo cotidianamente el rezo familiar del rosario en la finca de Palermo, concluía cada Gloria con un "secuderam num principium nuncansemperseculaseculorum". ${ }^{1}$ También los viajeros y los inventarios de las testamentarías dan cuenta de la presencia de imágenes y estampas en ranchos muy humildes de la campaña bonaerense. En otras palabras: si bien la presencia del clero y su capacidad de coerción era limitadísima en general y sobre todo en las áreas rurales, aun en esas zonas libradas a sus propios medios, donde las creencias y las prácticas son más autoconstruidas que en las ciudades, el apego al catolicismo parece haber sido más habitual que su olvido.

4 ¿Puede considerarse suficiente ese rasgo para afirmar la idea del "país católico"? No somos nosotros los primeros en preguntárnoslo, porque antes de que la cuestión ocupara un lugar en nuestras agendas de investigación fue objeto, como bien se sabe, de célebres debates. En los últimos decenios del siglo XIX se discutía a menudo, en la prensa y en el ámbito parlamentario, si la Argentina podía seguir considerándose católica y en qué sentido. Los defensores de los "derechos de la Iglesia" solían alegar que el catolicismo era la fe de la mayoría y que constituía un rasgo de la identidad nacional, de hondas raíces históricas, que no se podía ni se debía desconocer. Quienes se oponían a tal argumento desde posturas radicales solían replicar que con tal afirmación se pasaba por alto no sólo la diversidad presente sino -y sobre todo- la futura, que consideraban tan ineluctable como deseable. En medio de los defensores de una y otra posición, pero más cerca de los primeros que de los segundos, solían posicionarse los funcionarios del gobierno de turno, 
que por encima de sus creencias personales debían poner los deberes que comportaba el desempeño del cargo. Porque las posturas en relación con este punto estuvieron dictadas, muy a menudo, por las necesidades que imponía la política. Furibundos anticlericales en la oposición cambiaban de discurso cuando pasaban al oficialismo, y viceversa. Vuelvo a traer el ejemplo de Sarmiento, que en 1868 declaró que en tanto presidente de un pueblo católico debía proteger la religión independientemente de sus ideas -aclarando, de paso, que si la masonería llamaba a oponerse a ella, había sido vilmente engañado al ingresar a una logia-, pero como opositor a Roca no dejó de acusar al gobierno de connivencias con la Iglesia. Desde luego las condiciones variaron enormemente entre la presidencia de Sarmiento y la de Roca, pero el pasaje del gobierno al llano tuvo también su parte. Razones políticas y obligaciones inherentes al cargo podían hacer que Eduardo Wilde elevara en 1884 un proyecto de ley pidiendo fondos para cubrir los gastos de instalación del obispo electo de Córdoba, o que Emilio Gouchon pidiese en 1901 la excepción del servicio militar de los miembros del clero secular y de los ministros de todas las religiones.

5 A lo que voy es que a mi juicio el "mito de la nación católica" que cobra vigor en el período de entreguerras no surge simplemente de una reacción católica frente al "Estado liberal", como Zanatta argumentó en su momento, sino que es el fruto de un desarrollo más complejo: el de las derivas de la laicidad argentina entre el Ochenta y el Centenario. Más allá de las posturas personales de los actores, favorables o contrarias que fueran a la idea del país católico, la realidad aconsejaba desoír los discursos radicales de uno y otro signo para evitar fricciones, tensiones o conflictos cuyos costos habrían de ser sin dudas superiores a los beneficios, tanto para el Estado como para la Iglesia. Lo que caracteriza a la Argentina, en relación con otros países de mayoría católica, es que la ponderación de la relación costos-beneficios poseía la misma polaridad para protagonistas que en otro contexto se habrían enfrentado violentamente. La peculiar laicidad argentina jugó un rol determinante en la construcción de la imagen del país católico. Frente a las posturas a menudo radicales de los anticlericales opositores, la conservación del vínculo entre Estado e Iglesia -que si nunca dejó de juzgarse oportuna cobró mayor importancia a partir de la segunda presidencia de Roca- obligaba a afirmar, por parte de funcionarios cuyas ideas personales en materia religiosa carecían por completo de relieve, la idea de que el catolicismo ocupaba -y siempre había ocupado- un lugar cuanto menos relevante en la vida del país. En otras palabras, creo que las necesidades políticas del cambio de siglo no fueron ajenas a la definición del "mito de la nación católica", que en ese sentido, aunque resulte paradójico, tiene también sus raíces laicas. En tal sentido ese mito -que sería más apropiado considerar una leyenda- cumplió entre otras una función etiológica: la de explicar por qué la Iglesia y el Estado argentinos permanecían unidos cuando en todos los demás países latinoamericanos se los separaba jurídicamente.

6 A partir de ese momento de inflexión finisecular, como se sabe, la idea de la nación católica fue ocupando mayores espacios en discursos parlamentarios, notas periodísticas, sermones, alocuciones oficiales, actos escolares y desfiles militares. Pero debajo de ese plano discursivo bullía una sociedad muy diversificada en cuanto a sus creencias y prácticas, dentro y fuera de un catolicismo cuya jerarquía eclesiástica, aunque sin duda más capaz que antaño de imponerle sus directivas, no lo fue nunca lo bastante como para lograr homogeneizarlo en la medida en que lo juzgaba necesario. Los estudios de Diego Mauro y de Miranda Lida sobre las manifestaciones católicas del período de entreguerras muestran que la utilización de una cierta tecnología de la movilización, sumada a 
intereses más bien ajenos a lo que solemos caratular como "religioso" (como el deseo de esparcimiento y el turismo), eran más eficaces a la hora de convocar multitudes que la prédica del famoso mito.

7 Para concluir, no creo que exista una "fuerte relación" de la Argentina con el catolicismo, como dice Lida, ni que el catolicismo sea un "factor crucial de la vida política y social" del país, como dice Semán. Si de lo que se trata es de evaluar su relevancia, resulta imprescindible distinguir períodos históricos, niveles de análisis, sectores sociales, ámbitos regionales y otras variables. Porque si incurrimos en afirmaciones tan generales muy fácilmente podemos acabar cayendo en las trampas más sutiles de la leyenda. Es posible, como sugiere Lida, que el primer congreso eucarístico internacional que se realizó en América Latina haya tenido lugar en la Argentina porque se la consideraba un país católico, pero habría que probarlo. Habría que explicar, en principio, por qué el primero se realizó en la Francia de la Tercera República, como así también buena parte de los sucesivos $(1882,1886,1888,1894,1897,1899,1901,1904)$, o por qué el octavo se celebró nada menos que en el Imperio Otomano. Tal vez en el período de entreguerras los criterios para elegir las sedes hayan variado y para la definición de la del congreso de 1934 haya tenido de veras peso la imagen de la Argentina como "país católico". Pero el hecho de que el de 1924 se haya reunido en Ámsterdam, el de 1926 en Chicago, el de 1928 en Sidney y el de 1930 en Cartago me induce a suponer que no es así. Más bien me inclino a pensar que el criterio era apuntalar a Iglesias a las que se consideraba promisorias, pero es una hipótesis. Me parece más improbable todavía que el colegio cardenalicio haya tenido en cuenta la nacionalidad de Bergoglio -que no es el primer papa extraeuropeo, aunque es cierto que no había uno desde Gregorio III- a la hora de elegirlo para desempeñar el ministerio petrino.

La reflexión sobre nuestra labor intelectual y el diálogo interdisciplinario, de los que el presente intercambio es tan buen ejemplo, deberían ayudarnos a escapar de las redes de esta leyenda que se ha demostrado tan capaz, como han señalado otros colegas en sus intervenciones, de permear no sólo los discursos de funcionarios o de obispos, sino también nuestra forma de encarar el estudio de la religión.

\section{Miranda Lida}

La idea de la nación católica vuelve una y otra vez en los debates sobre religión y sociedad en la Argentina contemporánea; parece que no pudiéramos despojarnos de ella. La discutimos, la denostamos y la vemos casi en todas partes. De tan pregonado y difundido, el mito quiso hacerse verdadero, aunque sólo fuera a fuerza de repetir hasta el hartazgo ideas bien rumiadas de cómo es, debió haber sido o deberá ser la Argentina. No obstante, el mito no deja de ser un mito, por más omnipresente que parezca. Si el país no era religiosamente homogéneo en el siglo XX, así como tampoco lo era en ningún otro sentido, de todas formas era fácil hacerse la ilusión, la fantasía, de que había una signo identitario que amalgamaba a todos, más allá del idioma, no siempre idéntico ni homogéneo en un país de inmigración. La nación católica es fruto de una ilusión, un espejismo que se suma al que nos señala Di Stefano. Con esto, no pretendemos negar, ni mucho menos, que se hablara en estos términos en amplios sectores de la jerarquía eclesiástica, por supuesto. El discurso estaba profundamente enraizado en la Iglesia Católica argentina. Sin embargo, ¿no hay acaso una fuerte distancia entre el discurso y las 
prácticas en muchos fenómenos históricos y sociales? Más todavía, ¿esta distancia no podría llevarnos a distorsionar nuestro propio objeto de investigación?

Creemos que hay espejismos, también, en la "nación católica". El discurso se agigantó hasta tal punto que se pierde de vista que el catolicismo podía ser menos compacto, incluso en los años treinta, de lo que parecía a simple vista. En otro lugar propuse la metáfora del "gigante con pies de barro" para referir al catolicismo militante de entreguerras. Quiero volver sobre esta misma idea, por lo que aporta no sólo para comprender el propio período aquí estudiado, sino por sus implicancias de más largo alcance, en especial, a la hora de pensar la relación entre la sociedad argentina y el catolicismo, en relación además con la cultura y la nación. Desde otra perspectiva, Frigerio, Ludueña y Semán insisten también en problematizar la nación católica.

11 Así, pues, la década de 1930. Fue caracterizada en reiteradas ocasiones como una época de fuerte avanzada clerical, cuya expresión más elocuente habría sido la celebración en Buenos Aires del XXXII Congreso Eucarístico Internacional de 1934, al que asistieron autoridades civiles, militares y religiosas de todo el país, así como también infinidad de visitantes y dignatarios extranjeros. Ya sea como consecuencia de la crisis del liberalismo que tuvo lugar en la posguerra en el plano internacional; por los propios avances de la Iglesia, a fuerza de presionar sobre los gobiernos de turno; por su red de instituciones y asociaciones laicales bien enraizadas a nivel territorial; por su capacidad de movilización de las masas, ensayada desde años previos en infinidad de circunstancias; por su capacidad de transmitir valores fáciles de asimilar para amplios sectores sociales en ascenso, como la decencia, las buenas costumbres, el decoro, las expectativas de una sociedad previsible, segura y ordenada. Todo ello conducía por una u otra vía a que el catolicismo se hiciera cada vez más visible en la sociedad argentina. De esta manera, la integración abigarrada del territorio nacional a través de los medios de transporte y de comunicación (así, por ejemplo, con el desarrollo de la red vial y de la radio) encontró su correlato religioso en la red cada vez más intrincada de parroquias, diócesis y arquidiócesis que se estableció en el país en esos años. Los congresos eucarísticos, a su vez, fomentaron los viajes de amplios actores del universo católico a lo largo del país y potenciaron a través de su transmisión por la radio, como nunca antes, la palabra de los oradores más descollantes, en especial, de los sacerdotes e intelectuales católicos, que cobrarían así una visibilidad social inusitada. De esta manera, el catolicismo, fortalecido por el credo integrista, de carácter militante, monocorde y compacto, demostró una fuerza expansiva que llamó poderosamente la atención de propios y extraños, para bien o para mal, a gusto de cada cual.

12 No obstante lo vigoroso que puede parecer a primera vista este catolicismo de los años treinta, es pertinente aquí insinuar que encontraba también sus propias limitaciones: si la Iglesia tanto se jactaba de los logros obtenidos, y necesitaba reafirmarlos a cada paso, es quizás porque esos logros estaban montados sobre bases más endebles de lo que se daba en admitir. Se proclamaba a los cuatro vientos el renacimiento católico y el fortalecimiento de una nación en clave católica, sin embargo las cosas no funcionaban tan bien como se decía: las parroquias crecían a pasos más lentos de lo que se las dibujaba en el papel; las diócesis se creaban en lo formal pero no se les daba suficiente presupuesto como para funcionar debidamente; se proyectó una catedral monumental para Buenos Aires en 1934 pero por razones presupuestarias nunca se pudo iniciar su construcción, a pesar de todos los sueños de grandeza que le estuvieron asociados; la gente se afiliaba a la Acción Católica pero era volátil y no permanecía en ella a largo plazo, así como no se 
sometía de buen grado a las duras exigencias de la militancia religiosa, demasiado exigente para el hombre común; las multitudes iban a los congresos eucarísticos, que duraban pocos días al año, pero no cumplían regularmente con los preceptos religiosos más básicos, los de todos los días; escuchaban la misa por la radio y a muchos oradores católicos que hablaban frente al micrófono y vendían por miles sus libros, y sin embargo, no asistían con regularidad a la misa dominical. Dicho de otra manera, el discurso no se condecía del todo bien con las prácticas, como suele ocurrir en infinidad de procesos históricos, y la retórica integrista visceral y agresiva que llevó a decir que la Acción Católica era una milicia, convivió con el hecho de que era también un espacio de sociabilidad en el que había funciones de cine y otras actividades recreativas que procuraban servir de atractivo para con la gente común, incluso para los jóvenes y los niños. Hoy en día se ha discutido incluso el número de socios que conformaron la ACA, al punto de poner en duda la imagen que se tenía habitualmente acerca de sus dimensiones, alcance y fortaleza.

13 Estos solos datos bastan para sugerir que el integrismo católico logró efectivamente una gran exposición pública gracias a la fuerte llegada que la Iglesia Católica tuvo en la sociedad y en los medios de comunicación, pero habría estado lejos de tener el arraigo profundo que hubiera exigido en caso de pretender hacer de cada cual un católico verdaderamente integral. Había que resignar calidad en aras de la mayor cantidad de fieles; para el caso no importaba que muchos de ellos no supieran hacer bien la genuflexión (los boletines parroquiales, por las dudas, enseñaban cómo hacerla, porque no se podía pasar por alto hasta qué punto muchos de sus lectores lo ignoraban). Poco contaba. De lo que se trataba era de lidiar una suerte de remozada Kulturkampf, con las armas y las formas del siglo XX.

14 Los historiadores -en especial los historiadores- hemos estudiado cuidadosamente los vínculos políticos que la Iglesia tejió con el poder, en especial durante los gobiernos militares o de dudosa legitimidad en la historia argentina contemporánea. Sin embargo, uno de los terrenos en los que la Iglesia Católica pretendió lidiar una batalla más imperceptible tal vez, pero no por ello menos importante, es la cultura. La relación entre cultura y catolicismo está en el centro de la argumentación de Ludueña, y desde otro lugar, también lo aborda José Zanca en su último libro. La democratización de la cultura, fenómeno en expansión desde fines del siglo XIX, era un terreno tanto o más preocupante para la Iglesia que el sufragio universal, la escuela pública o el ascenso social de los sectores medios o populares. La democratización de la cultura entrañaba gravísimos riesgos que la Iglesia advirtió muy tempranamente: el libro barato, la radio, la prensa popular, lejos de ser factores de aculturación de las masas, podían ser vistos como amenazas profundas que ponían en jaque los valores tradicionales, las jerarquías sociales, las relaciones de género (en este sentido, nada más preocupante para la Iglesia que las lecturas juveniles de las adolescentes). Si a ello le sumamos la vasta red de instituciones culturales (bibliotecas, entre otras cosas) creadas y difundidas por socialistas y anarquistas en las ciudades más populosas de la Argentina, tanto más urgente era para el catolicismo tomar cartas en el asunto. Su intervención en el campo cultural fue muy temprana, aunque quedó opacada totalmente por el debate político sobre la educación, con motivo de la ley 1420. Ya en la década de 1880, sin embargo, se libró la Kulturkampf del catolicismo argentino: se avanzó sobre el libro popular, se denostó la literatura criollista, plagada de moreirismo a fines del siglo XIX y se fomentó la creación de bibliotecas parroquiales y editoriales católicas, entre otras cosas. 
El siglo XX ofreció un terreno mucho más amplio todavía para librar la batalla cultural, puesto que trajo consigo una expansión casi sin límite de las modernas industrias culturales. La Iglesia argentina se interesó por ellas, e intentó intervenir e influir sobre ellas, en un sentido moralizante, incluso mucho antes de que el Vaticano publicara sus primeras encíclicas al respecto. Así, por ejemplo, su temprana preocupación por el cine (a causa de su posible influencia moralmente perniciosa), que aparece en el catolicismo argentino hacia mediados de la década de 1910. La encíclica al respecto data sin embargo de 1936 (Vigilanti Cura, de Pío XI). Y así sucesivamente. Las industrias editoriales católicas se desarrollaron en este mismo período, y lo mismo cabe decir de la prensa de masas y la radio: la Argentina llegó a tener con el diario El Pueblo una suerte de "multimedio" (diríamos hoy), que publicaba libros, folletos, revistas, tenía su propia agencia de noticia, a la par que tenía espacios en la radio, donde difundía sus noticieros. El Pueblo calcó el modelo norteamericano de diario tabloide, ágil, moderno y alentó el periodismo católico, militante y comercial al mismo tiempo. Copió, además, al diario Crítica, muy popular en entreguerras, pero poco aceptable para los católicos. La Iglesia creyó, así, que podría hacer realidad su ambición de alcanzar a todos los argentinos con su voz, con su palabra. En pocas palabras, haría realidad el sueño de la nación católica. A veces creía estar bastante cerca de lograrlo: el Congreso Eucarístico Internacional se transmitió por radio en todo el país y también en el extranjero. De esta manera pretendía exorcizar un medio de comunicación popular plagado de tangos y radioteatros de sabor arrabalero, juzgados de mal gusto en ámbitos católicos. Sin embargo, el tango estaba demasiado arraigado en la cultura argentina como para extirparlo por la sola prédica de Monseñor Gustavo Franceschi que en la revista Criterio despotricaba con frecuencia contra él. La Kulturkampf católica era a veces una batalla perdida. Dicho de otro modo: la nación católica tenía sus limitaciones.

16 A diferencia de otras confesiones religiosas que no tuvieron, o no aspiraron a tener, tamaña expansión en el campo cultural -el protestantismo hizo sus avanzadillas en el terreno del libro popular pero no fue tan lejos como los católicos en las demás industrias culturales, da la impresión-, el catolicismo sentó sus reales en la cultura de masas y atacó con una contundencia militante en ese frente. Todos recordamos las campañas moralizantes contra películas y obras de teatro, juzgadas subidas de tono por la Iglesia, que se desarrollaron en las décadas de 1960, 1970 e incluso 1980, en pleno destape... Y hoy en día, uno de los premios más tradicionales de la televisión argentina se llama Santa Clara de Asís. La batalla en el campo de la cultura, pues, no ha concluido.

\section{Alejandro Frigerio}

Comencemos, primero, por la historia. Como se desprende de los textos de Di Stefano y Lida, parece quedar claro que si observamos el panorama histórico local, la trayectoria ideal "monopolio-desinstitucionalización-mercado (o "catolicismo a la carta")" se hace bastante menos creíble que postulándola a la luz de determinadas lecturas de la teoría sociológica sobre la secularización y sobre la religión en el mundo contemporáneo (Frigerio, 2007). Di Stefano afirma muy claramente que "la idea del monopolio católico es inadecuada, incluso en referencia con los períodos en los que su vigencia ha sido menos cuestionada por parte de los historiadores" (la era colonial y la revolución). La histórica falta de personal religioso suficiente por parte de la Iglesia, los procesos inquisitoriales, las prácticas de las poblaciones locales indígenas y africanas, la esporádica -ni siquiera 
anual presencia- de muchos supuestos feligreses, aun en las ciudades, muestran que "en la época colonial el catolicismo es monopólico" (tan solo) "en el plano jurídico". Por lo tanto además del "mito de la nación católica" (al que hace referencia Lida, vía Zanata) para este autor también existiría un "mito del monopolio católico" sostenido -aunque no sólo- por la historiografía "decididamente confesional" (aquí me pregunto, ¿habrá que empezar a hablar de una "sociología confesional"?). Si "la historiografía 'laica"', no la ha puesto suficientemente en cuestión, señala, es porque en parte abona su "rudimentaria concepción de la secularización" y no puede apreciar que "no hay ni siquiera entre la colonia y el siglo XIX un 'antes' católico al que sigue un 'después' diversificado" (dialogando con Frigerio, 2007).

El trabajo de Lida también desmiente visiones demasiado unilineales del desarrollo, la involución o la desinstitucionalización católica, mostrando más bien la existencia de distintas olas de actividad que se despliegan y repliegan (de creación y movilización de movimientos juveniles y obreros, de surgimiento, popularidad y decaimiento de concepciones integristas o más orientadas a lo social, de misionalización y parroquialización de sectores populares) creando momentos de diferente catolización de la sociedad -promovidas por actores con distintos tipo de relación con la institución, que intentan crear un monopolio donde no lo había y que afectan de manera desigual las ideas acerca de la nación, de lo político, de lo social y de lo religioso-. Actividades y olas que obviamente muestran la importancia del catolicismo en la sociedad argentina -que nadie puede negar- pero no como un todo contenedor que abarca religión, patria, identidad personal y colectiva y que se va desgranando sucesivamente, sino como una serie de movimientos diversificados que en distintos momentos y con variante intensidad van afectando, de maneras que aún debemos comprender adecuadamente, diversas áreas de la sociedad y de la vida de los individuos que la componen. Repito, en este sentido la macro-teorización sociológica sobre la "recomposición de la religión en la modernidad" y la historia local y concreta de la institución Iglesia Católica (que en nuestro país suelen ser concebidos como equivalentes) no se corresponden adecuadamente.

Desde la antropología aparecen las voces (Ceriani, Ludueña, Semán) más preocupadas con las conceptualizaciones y las teorías, y los intentos por problematizar el sentido común académico que parece estar haciendo que buena parte de los trabajos locales sobre religión sean más una comprobación rutinaria de lo que se desea afirmar que una exploración novedosa innovadora -una afirmación propia que reconozco es manifiestamente provocadora y, si tomada literalmente, también injusta.

No me preocuparía, en un principio, que nuestras definiciones de "religión" (o las que podamos contemplar para reemplazarla como la de "espiritualidad") coincidan o no con la de nuestros "nativos" (ver Ceriani, 2013 y también en este debate). En sociedades postindustriales (y quizás en otras más pequeñas también) los nativos no suelen ponerse de acuerdo entre ellos y tampoco usar los términos y conceptualizaciones de manera coherente a través del tiempo. Sin embargo, y como bien señala Ceriani, la aparición o popularidad de determinados términos sí puede dar cuenta de nuevas formas de relación con el mundo espiritual (o suprahumano, o divino/inmanente) y pueden ser una necesaria puerta de entrada a su comprensión. La reflexión acerca de superposiciones o diferencias entre usos nativos o académicos también resulta vital para un mejor conocimiento de la manera en que ambos grupos entienden estas realidades. La resonancia de estos términos con el espíritu de los tiempos -como señala Ceriani, con 
narrativas multiculturales o poscoloniales- también permite entender su popularidad y legitimidad -tanto social como académica.

21 Si los nativos no necesariamente deben ser coherentes con su comprensión y utilización de determinados términos, quienes sí deberíamos hacerlo, sin embargo, somos los cientistas sociales, y por lo tanto, como ya he planteado con anterioridad (Frigerio, 2013; Frigerio y Wynarczyk, 2013) no sólo deberíamos tener en claro qué fenómenos sociales analizaremos bajo el término "religión" (o el que decidamos usar) sino también aplicarlo concienzuda y coherentemente. $\mathrm{Si}$, como afirma Semán en este debate, puede suceder que "las definiciones de religión que poseemos al inicio de una investigación son desmentidas por nuestro objeto", deberíamos redoblar los esfuerzos para que esto se deba a la complejidad del objeto de estudio y no a una formulación o aplicación incorrecta de la propia definición. Los deslices tácitos entre las diferentes dimensiones de vigencia y "hegemonía" católica (en los planos analíticamente distinguibles de -al menos- la construcción de la nación, de la juridicidad, de la política y de las creencias y prácticas religiosas de los individuos) son ubicuos y también se hacen evidentes en este debate. Una preeminencia en alguno de estos planos en un determinado momento no la garantiza en los otros ni tampoco para siempre. A estos deslices de sentido debemos estar atentos para no reificar monopolios católicos por todos lados y en todo momento.

Así, se podría proponer que el catolicismo es mejor para construir identificaciones nacionales que para regular o pautar las relaciones entre los hombres y los seres suprahumanos -una definición mínima posible de "religión". Como sugiere la actual "Papamanía" se lo podría pensar como más exitoso construyendo comunidades imaginadas que proponiendo seres sobrenaturales/suprahumanos y formas adecuadas de relacionarse con ellos -vista la innegable variedad de creencias y prácticas que manifiestan los "católicos" argentinos. Para comprender esta diversidad y sus orígenes y concepciones distintas de, y externas a, "el catolicismo" hay que trascender tanto una visión excesivamente institucionalista -que ve a la Iglesia como la fuente de toda práctica e identidad religiosa- como una (difusamente) culturalista, que plantea la eficacia (simbólica, para los analistas, diría Ludueña) de la omnipresente, omnicomprensiva pero nunca bien definida "matriz cultural católica" que permearía buena parte de nuestras prácticas, aún las no religiosas. Esta amalgama reactiva entre "cultura" y (una determinada) "religión" aún no ha sido suficientemente conceptualizada, teorizada, ni comprendida o comprobada y parece basarse en la presuposición previa y aceptación acrítica previa de la idea del "monopolio católico".

Una vez que tenemos claro qué entendemos por "religión" (como fenómeno social a analizar), debemos ver cuál es su relación con las "religiones" (específicas). Como señaló Pierre Sanchis hace ya un tiempo, "¿el campo religioso será todavía el campo de las religiones?". Coincido con la relevancia del planteo -aunque no necesariamente con su análisis. Un énfasis excesivo en la sistematicidad de las creencias y en determinadas formas organizativas de transmitirlas (un énfasis desmedido en la institución, y especialmente en los tipos "iglesia" y "secta" derivados de la tradición cristiana) o en su defecto, en formas individuales e idiosincráticas de practicarlas ("misticismo"), hace que perdamos de vista la cantidad notable de grupos lábiles por los que los individuos transitan y mediante las cuales reciben, elaboran, transforman y ponen en práctica, sus conocimientos religiosos (Frigerio, 2013). Me parece que a esto apunta Ludueña (2013) cuando aboga por una perspectiva más relacional de la religión o cuando sugiere en este debate, "Es necesario comenzar a especular sobre religiosidades más ligadas a 
asociaciones coyunturales abonadas por intereses particulares, que en otras solo ordenadas alrededor de mecanismos institucionales de poder y condicionamiento estructural". Su término "sociabilidades de coyuntura" parece particularmente apropiado para visualizarlas. Coincido con que es necesario un modelo más "denso" de las elecciones de los individuos respecto de sus prácticas religiosas, visualizándolas siempre como insertas (embedded) dentro de redes o tramas de relaciones sociales y de procesos de compromiso/conversión/tránsito que no involucran una sola elección sino varias a lo largo del tiempo (algo que, aún resaltando las bondades de determinada lectura del paradigma de las economías religiosas, ya he señalado en Frigerio, 2000, p.44). Eso no disminuye la importancia de la(s) elección(es) personal(es), pero sí las hace más complejas y exige un mayor esfuerzo académico por entenderlas. También es necesario resaltar que no hay una opción sino una serie de ellas que a lo largo del tiempo se sostienen o modifican a través de relaciones que se establecen con diferentes personas y agrupaciones de consistencia muy disímil, en contextos coyunturales determinados. Actualmente, navegamos entre los peligros de una visión demasiado institucionalista (que representaría la situación ideal en el "pasado") y otra demasiado individualista (que para algunos representaría el "presente"); tenemos por lo tanto o creyentes fielmente congregados y sobresocializados (evocados bajo el concepto "religión") o buscadores ( seekers) o "creyentes a la carta" hiperindividualizados (evocados por el concepto "espiritualidad"). Además, como bien mostró Carozzi (2000) un discurso nativo que enfatiza e intenta demostrar y convencer de la autonomía individual en la búsqueda religiosa es perfectamente compatible con (más, de hecho depende de) el pasaje por una cantidad muy variable de conferencias, talleres, encuentros y grupos de meditación, espiritualidad o autoayuda de muy variable consistencia y permanencia en el tiempo. El (mítico) "individuo autónomo" sólo hace sentido en contraposición a uno (igualmente falaz) "fielmente congregado".

Las ideas de "grupos lábiles" o de "sociabilidades de coyuntura" nos permitirían hacer visibles las redes y agrupaciones sociales de distinto tipo, formas intermedias e intermediarias de producción y circulación de conocimiento "religioso" o "espiritual", cuya importancia se pierde entre visiones demasiado culturalistas, individualistas o institucionalistas. Todos estos grupos, ideas religiosas/espirituales y prácticas muy diferentes y nada "católicas" desaparecen de nuestro radar si nos quedamos con la identificación pública que la mayor parte de sus practicantes realizarían, que es la de "católico".

En el campo religioso, como bien señala Semán, "no compiten tan sólo distintas fórmulas para comprender la eucaristía o administrar la salvación", ya que, como afirma "definir las cosas de esta manera sería hacerlo con demasiado centramiento en las definiciones institucionalizadas de la religión por el catolicismo y el protestantismo". Para Semán, en el campo religioso: "se confrontan concepciones que tienen como bien religioso a la salvación, pero también la sanidad, la prosperidad, etc. (...) compiten el consuelo de la cruz, la promesa de sanación, las búsquedas interiores a través de la dieta y los ejercicios respiratorios (...) es un campo de disputa en el que se apuntalan, expresan y refuerzan no solo definiciones de la religión sino, nociones de persona y alteración de las que las 'religiones' son un elemento co-participante" (en este debate, y también en Semán, 2013).

Finalmente, la detallada contribución de Giménez Béliveau muestra, en su primera mitad, la perspicacia de los buenos análisis sociológicos, y, en su segunda mitad, nuestra dificultad para lidiar con las "carreras religiosas" de los argentinos no comprometidos 
con agrupaciones religiosas (la mayoría de la población). Una noción fuerte de identidad (en realidad, identificación) que la equipara con "pertenencia", "compromiso" o "afiliación". lleva a una interpretación que tiene como interlocutor constante y omnipresente al "catolicismo" siendo que, desde otras conceptualizaciones (como las que estamos proponiendo) esa interlocución sería tenue, difícilmente podría vista como "desafiliación" y seguramente entrarían a tallar otras voces y otros agentes con una relevancia similar. La excesiva identificación entre afiliación religiosa declarada = religión lleva a agrupar en la misma categoría de "indiferentes religiosos" a los creyentes que no se identifican con una determinada religión con los ateos y con los agnósticos. Es más que probable, tomando en cuenta todo lo propuesto hasta el momento en este debate, que estos "creyentes-que-no-declaran-pertenecer-a-alguna-religión" tengan más similitudes con quienes se declaran católicos pero no participan regular ni intensamente de actividades de instituciones católicas (la mayoría de la población) que con los ateos o los agnósticos. Una elección teórico-metodológica (que debe ser entendida como sólo una entre varias posibles) crea entonces un "grupismo" reificado.

De cruces y diálogos como el aquí sostenido podemos, entre todos, cuestionar nuestras perspectivas naturalizadas $\mathrm{y}$, eventualmente, entender mejor la complejidad y "pluralidad jerarquizada" (Semán) de nuestra Argentina diversa.

\section{Gustavo Ludueña}

En esta segunda parte deseo retomar otro de los rasgos antes citados del modelo del monopolio, y me refiero en especial a la noción de "campo", para descubrir luego su articulación con una idea que encuentro -aunque de manera no explícita- en el resto de las participaciones que componen este dossier. Esta presencia invisible de la que todos hablan, o aluden como artilugio heurístico para una explicación sobre la diversidad, me parece que está dada por la cultura. Tal aspecto, por tanto, me permitirá justificar de algún modo mi insistencia en el valor de un foco que alumbre los procesos de acomodación para comprender la diversidad religiosa en nuestro país. La acertada frase de Roberto Di Stefano acerca de que "[n]o hay ni siquiera entre la colonia y el siglo XIX un 'antes' católico al que sigue un 'después' diversificado", una aserción que por mi parte asumiría como válida para la centuria subsiguiente, se aproxima a formular una respuesta a la pregunta incómoda que manifesté en mi primer escrito. Los casos de Sarmiento y Musso, que como sugiere tácitamente el autor estuvieron lejos de ser los únicos, mostraron las tensiones del anticlericalismo decimonónico con el catolicismo. De forma idéntica, el breve caso que introduje sobre una adherente al espiritismo y su paradojal relación con el mundo católico, se adiciona a los otros ejemplos del pasado y del presente (como los mencionados por César Ceriani) que, entiendo, ponen en jaque ciertas construcciones teóricas que, amén de tener un origen disciplinar evidente y por lo tanto una modalidad singular de examinar la realidad social, comienzan a evidenciar las debilidades explicativas del modelo del monopolio. La imposibilidad empírica de establecer un hito historiográfico fundante entre un estadio de "catolicismo" y otro de "diversidad", echa por tierra el plan de construir una respuesta por la afirmativa a mi pregunta inicial; eso aun cuando, como arguye Di Stefano, "en cierto sentido la Argentina [pueda ser] un país más católico que otros". A diferencia de la sinécdoque, aquí no podemos tomar la parte por el todo. 
29 La aparición pública de la Iglesia Católica, entonces y después (y, por supuesto, también ahora), no fue ajena al empleo de tecnologías de representación que, como lo ilustra Miranda Lida, se materializaron en medios radiales, editoriales y de prensa escrita (así como en las incipientes estructuras escolares y sanitarias); lo cual, a todas luces, apuntala una tesis por la difusión cultural del catolicismo allende los acotados límites institucionales católicos. Sin embargo, más cerca de la experiencia actual, esta percepción se robustece a la sombra de los hallazgos que exhiben trabajos recientes que, como los de Pablo Semán y Joaquín Algranti, exploran el devenir de diferentes religiosidades en la música y la industria del libro (entre otras manifestaciones más heterodoxas de la cultura material masiva). En este orden, es claro que existen prácticas y creencias religiosas que son más "exitosas" que otras en función de la divulgación social que logren alcanzar. Al punto que el máximo trofeo sociológico de una religión no radicaría tanto en ganar adherentes, ni en la legitimidad o adquisición de "capital simbólico", como nos invita a pensar la mirada fundada en el paradigma del monopolio hasta ahora soberano en nuestra academia, sino en el grado en el que algunas de (o todas) sus propuestas prácticas y cosmológicas alcancen el estatus de naturalidad del sentido común que proviene solo del mandato tácito que nos impone la cultura de la époque.

30 El hecho de que podamos escuchar a un católico, o incluso a un sacerdote en su homilía dominical, recurrir a la noción (ya vox populi) de "energía", o inclusive que se nos muestre en los medios de comunicación al papa con su médico chino y sus terapias orientalistas (un horizonte semántico bien distinto tanto como distante del panteón católico) habla de la apropiación de flujos discursivos (i.e., haceres, saberes y decires) que evaden con sutil pericia los alambrados, o incluso las capilaridades, que podamos asignarles a los campos. En esta línea, el catolicismo puede ocupar -aunque cada vez con mayor dificultad- el más alto escalón en el podio; pero, por consiguiente, está lejos -al igual que siempre, a no equivocarse- de ser el único. Dicho de otra forma, cuando al menos parte de los componentes morales y de la percepción cosmológica en general ofrecida por una religión resultan aceptados por su estatus de "normalidad" en la sociedad para encontrar su lugar vital como unidad de un esquema interpretativo, sea global o parcial en el sentido común de las personas, es cuando la legitimidad implícita se sobrepone con eficacia suprema a la -eventualmente- canónica o jurídica. La diversidad participa de este juego colectivo en el ciclo diario, y en no pocas ocasiones dialoga en ese discurrir con el mundo católico y con otros. Estudios seminales como los realizados por María Julia Carozzi, y más recientemente los de Catón Carini, Rodolfo Puglisi, Víctor Hugo Lavazza, Alejandro Otamendi y Nicolás Viotti, por ejemplo, muestran como adherentes a la Nueva Era, budistas, seguidores de Sai Baba, daimistas, platillistas, pero también evangélicos, espiritistas, convertidos al Islam y devotos del Gauchito Gil, entre otras configuraciones viables de vivencia espiritual, preservaron abiertos los canales simbólicos que los conectaron otrora con el imaginario católico. Lo diverso, en suma, interpela al catolicismo desde la posición de una alteridad imaginada que obliga a refiguraciones constantes de la mismidad.

31 Esto no necesariamente tiene que obedecer al corolario de la lógica previsible de un campo de fuerzas (en este caso religioso), una metáfora fisicalista demodé que -de modo alterno- acompaña a la otra más economicista del mercado, sino a las dinámicas reflexivas que despliegan sujetos que no fueron domesticados ni antes ni ahora, como la idea del cuentapropismo pretende implícitamente hacernos creer. La noción de campo (alternativa a la del antedicho mercado) es la base cardinal sobre la que descansa el 
modelo del monopolio; el primero es condición sine qua non para la existencia de este último. La presunción de una delimitación en el espacio social de algo ponderable como religioso (un ítem que sabemos que Bourdieu corrigió más tarde con la tesis supletoria de la "disolución" -como oportunamente nos lo recuerda Semán-); la racionalidad teleológica subyacente de una competencia por el capital simbólico y aun entre los actores sociales por los denominados "bienes de salvación"; y la división radical entre especialistas (los poseedores del saber) y los legos -sobre lo que me detuve con más amplitud en otro artículo-, son algunos de los ejes vertebrales que definen la existencia del campo religioso. Por lo tanto, es inevitable presumir que tal concepción opera bajo una voluntad taxonómica de la realidad. Así, las tribus que vemos condensadas en taxones tales como "evangélicos", "católicos", "espiritistas" e "islámicos", entre otros, regulan nuestra visual panorámica sobre la religiosidad. En adición a esta tribalización que es continuamente interrogada por clivajes transversales como los de secularización, modernidad, globalización, etc., no es factible identificar en la experiencia local un momento histórico específico en que el campo pasara de un estado concentrado a otro diluido, como el mismo Bourdieu lo afirmó en La dissolution du religieux (1987) cuando hizo años después la revisión crítica a su original y finamente elaborado Genèse et structure $d u$ champ religieux (1971). Todo parece indicar que, lejos nuevamente de la percepción a la que nos induce solícito el paradigma del monopolio, siempre estuvimos diluidos. En esta dirección, la incursión de la Nueva Era al promediar la segunda mitad del siglo XX, sumó más disolución a una atmósfera que ya era religiosamente líquida.

El campo religioso no solo está habitado por componentes susceptibles de ser catalogados como religiosos (o, ahora, espirituales -y aun "sagrados"-), como tampoco los otros campos no religiosos (e.g., económico, artístico, político, etc.) no son terrenos inhabitados para lo religioso. Podemos preguntarnos entonces, ¿cómo nos sirve en el análisis el campo para pensar y entender la diversidad que pretendemos investigar, más allá de revelarnos de que existen actores sociales que ostentan prácticas y creencias que pujan, suponemos $a$ priori, por obtener lo que convenimos en llamar capital simbólico? ¿En qué punto de ese campo o de qué forma ubicamos a Pancho Sierra (1831-1891), a la Madre María (1854-1928), a Cosme Mariño (1847-1927), o al profeta Benjamín Solari Parravicini (1898-1974)?, personajes que, entre muchos otros no tan conocidos, le pusieron carne al esqueleto estructural imaginario que surge del monopolio y de su campo aliado. ¿Por qué no ver en ellos, tomando a Bourdieu, a los "nuevos clérigos" (aunque viejos en términos historiográficos) en una retrospectiva más justa, y sobre todo más real, que nos indique las relaciones que tejieron con la sociedad en la que vivieron? El ensayo de las respuestas a estos cuestionamientos nos conduce a los laberintos de la cultura y de la acomodación de la que vengo haciendo mención. En función de este abordaje de la microacomodación, hay un punto que es nodal y que todavía no terminamos de entender ni de investigar que es el valor de los discursos y de las construcciones sobre la alteridad, lo que tiene que ver con los flujos discursivos que circulan en la sociedad. En el ciclo de la vida cotidiana, nosotros y los sujetos con los que nos cruzamos, estamos inmersos en los discursos del sentido común y de otros de otra clase; como lo son aquellos tan fundantes de verdad que provienen de la ciencia, la justicia y la religión. Es a través de ese sentido común, aliado de la reflexividad, donde se terminan moldeando estas matrices de relaciones que, por encima todo, afectan los esquemas de sociabilidad de los actores; aspectos sobre los que, en otras palabras, Alejandro Frigerio refirió desde una acertada inquisición al "grupismo" -lo que va en tándem con la referencia que hice acerca de las "asociaciones" trayendo a Bruno Latour-, y Verónica Giménez Béliveau desde lo que define como la "sociabilidad 
intensa" que deriva en la formación de las nuevas comunidades en los bordes liminares del catolicismo. Por eso, no es un tema nimio encarar esta cuestión que tiene que ver con los discursos del sentido común, la reflexividad y las relaciones sociales. La visión convencional confunde el protagonismo estatal del catolicismo, que tuvo un tiempo y espacio limitado, con la sociedad en su conjunto.

En cierto modo, puede afirmarse, los problemas de la idea de campo no son muy diferentes de los que experimentó en alguna oportunidad la noción de cultura. En el enfoque clásico que desarrolló la antropología, la cultura se basó en una ecuación que la equiparaba con el lenguaje y el territorio; es decir, una cultura era igual a un lenguaje y un territorio, hasta que la crítica posmoderna comenzó a mostrar los nuevos escenarios a los que estaban sometidos las sociedades complejas. Encuentro ahora al campo religioso en un dilema similar. Si hemos de emplear esa noción, como recurso heurístico para aprehender un conglomerado sociohistórico complejo de diversidades atravesadas por el clivaje de lo sagrado (un tópico que merecería un nuevo tratamiento en las discusiones académicas prosiguiendo los pasos que a nivel local nos dejaron las investigaciones de Eloísa Martín), puede aceptarse como un paisaje abierto de condensación no excluyente de actores, significaciones y prácticas que resultan ser objetos de sacralización para su uso en territorios que son mayormente distintos del originario (o que por lo menos no se agotan en él). La sacralización, un proceso simbólico en el que advierto que podemos ver el juego dinámico de las estructuras de la historia y de la cultura -siguiendo aquí a Marshall Sahlins-, puede ser igualmente un camino que, como la acomodación social que vengo apuntando, ilumine el tránsito sinuoso de la diversidad en estas latitudes. Me apresuro a decir que creo que incurrimos en error si pensamos que la sacralización es un proceso que solo se da en la llamada religiosidad "popular" (apelativo al que Frigerio escruta críticamente en su artículo). Tomar la posta que Martín dejó en relación a la constitución simbólica de lo sagrado para animarnos a caminar fuera del campo -y mucho más alejados ya del monopolio-, abrirá sin duda avenidas no circuladas aun que posibiliten trascender los obstáculos empíricos, teóricos y epistémicos en general que se derivan del binomio religión-espiritualidad allende los debates que se abren en torno a lo institucional.

En fin, esta perspectiva que trataría de abordar y problematizar nuestros sujetos diversos bajo otra conceptualización epistemológica tendría que focalizarse sobre las relaciones, los discursos y la construcción de matrices sociales. Debemos seguir más a los actores, a los procesos y los sentidos para entender más las relaciones, los fluidos y las historias. Pienso que nuestra academia está en un estadio óptimo para discutir y redefinir nuevas herramientas de aproximación y reflexión sobre los sujetos con los que trabaja. El desafío es diseñar metáforas que sean más explicativas de la diversidad que estamos ahora revisitando desde un locus renovado. Para concluir, trayendo nuevamente las expresiones que me llevaron a discutir el modelo hegemónico del monopolio, quisiera recordar que no estamos ni solos ni desinstitucionalizados, que siempre fuimos cuentapropistas y que, para tomar en préstamo y dar un giro diacrónico a la expresión del eximio Pierre Bourdieu, siempre estuvimos diluidos. No somos más heterogéneos hoy, por la sencilla razón de que ya lo fuimos ayer. En este tramo, el auxilio de más estudios de corte historiográfico, sea que ellos vengan de la sociología, la antropología, el folklore o la propia historia (como los que presentaron nuestros colegas en este dossier), se imponen para alumbrar áreas que todavía permanecen oscuras obliterando la posibilidad de ponderar, con un atisbo de precisión, lo que percibimos como diversidad. 


\section{César Ceriani Cernadas} religiosa" ofrecen, en primer lugar, un gratificante espacio de diálogo entre antropólogos, historiadores y sociólogos abocados al estudio de la religión en Argentina. Lejos de ser un hecho excepcional (aunque su concreción editorial en un debate como este es ciertamente inusual), podemos interpretar al mismo como un positivo "signo de los tiempos" que condensa una de las preocupaciones medulares que recorren las presentaciones: tender puentes sobre fronteras disciplinares para volver inquisitivamente sobre nuestros propios sentidos comunes académicos. Dialogando con Di Stefano, Frigerio, Giménez Béliveau, Lida, Ludueña y Semán se abre el juego a la reflexión sobre varios puntos que fertilizan recíprocamente nuestras contribuciones. De esta manera, en esta segunda comunicación me abocaré a señalar los principales tópicos que permiten articular miradas sobre los temas que aquí nos convocan, señalando asimismo algunas zonas conceptuales críticas que aún reclaman relecturas y nuevos posicionamientos.

Trasladar un término de origen económico como monopolio ("único vendedor") al escenario de las instituciones, creencias y prácticas religiosas encierra una dificultad analítica que no ha sido explícitamente puesta de manifiesto en este debate. La noción suele confundirse con la de hegemonía, emergente de la filosofía política gramsciana y ampliamente revisitada por los llamados "estudios culturales" y "pos-estructurales". En términos conceptuales, y más allá de sus críticas, esta última sería más acorde para pensar las relaciones de poder al interior de las sociedades nacionales, las instituciones eclesiásticas, las comunidades religiosas (con sus grados variables de institucionalización) y las acciones individuales de los agentes involucrados. La lectura de los trabajos presentados nos interpela así a comprender la complejidad implícita que conlleva la noción de "monopolio religioso católico". Pese a no discutir la plausibilidad explicativa de la noción de "monopolio", hay un acuerdo congruente en los trabajos presentados en observarla críticamente en tanto concepto adecuado para entender el devenir históricosociológico del catolicismo en Argentina (y su ingente variedad institucional, política, ideológica, ritual y experiencial), como la inherente diversidad "religiosa" y/o "espiritual" que caracteriza a este espacio nacional desde sus tiempos formativos o, como nos enseña Di Stefano, desde su pasado colonial. Junto a esto, las presentaciones nos ayudan a profundizar nuestro conocimiento sobre el proceso de mitificación que gestó la equivalencia estado-nación y catolicismo (apareamiento que, como ya nos había advertido Ludueña (2009), fue coextendido a la "cultura católica latinoamericana"). Es decir, el lugar central que tuvo el catolicismo en la "narrativa dominante de la nación" (Frigerio) forjada durante la conformación del estado en las últimas décadas del siglo XIX, tanto en sus instituciones eclesiásticas como en su supuesta capilaridad sociocultural. Esto nos permite analizar con otros ojos una dicotomía que durante largo tiempo ancló las percepciones antropológicas, sociológicas e históricas sobre la nación: la oposición tajante entre "liberalismo - catolicismo". Este dualismo maniqueo implicó asimismo el supuesto traspaso hegemónico del primero al segundo, para luego considerar que el quiebre del último dio emergencia e impulso a la "diversidad religiosa" argentina en los últimos treinta años. Por el contrario, las diversas indagaciones efectuadas por los colaboradores en este debate, junto a las producidas por estudiosos como Paula Seiguer y José Zanca (entre otros), complejizan ampliamente los vínculos claves entre ambos 
dominios, que distan mucho de ser homogéneos y compactos. Di Stefano sintetiza en su texto esta composición con la claridad que lo caracteriza, Semán refiere los efectos dispares de "la Santa Alianza de catolicismo e iluminismo" en la vida social argentina y Lida ilumina cómo en la reificación del mito de la nación católica en el período de entreguerras los medios masivos de comunicación y las llamadas industrias culturales aunque denostados ideológicamente por los integristas dados sus perniciosos efectos morales- fueron elementos constitutivos centrales en la reificación de dicha "nación católica imaginada". Esto nos habilita a pensar que la entreverada y por momentos conflictiva negociación histórica entre "liberalismo" y "catolicismo" decantó en la producción de la legitimidad moral de este último tanto en las configuraciones institucionales como en los imaginarios simbólicos de la nación. Asimismo, nos permite continuar la larga problematización sobre los modos sociales y políticos en que ambos constructos emergen de un proceso social que los engloba, limita y redefine a la vez: la mentada secularización.

La singular historia del catolicismo en estas tierras, como algunas de sus figuraciones contemporáneas, nos permiten observar en qué medida las vocaciones hegemónicas eclesiásticas conllevan inherentemente sus espacios de fugas, disputas, contestaciones y réplicas. Asimismo, en las diversas dinámicas vinculadas a la "religiosidad popular" y las "nuevas espiritualidades" se develan lógicas yuxtapuestas de reproducción y cambio sociorreligioso, acomodación y contestación simbólica de características asociativas o bien personales. En términos sociológicos, la cuestión remite al carácter segmentario del poder, al hecho de que el mismo "no puede ser nunca totalmente contenido dentro de las relaciones de autoridad" (Cohen, 1985) y a la necesidad de interpretar las relaciones de poder "en términos correlativos como fenómenos interdependientes y no como las manifestaciones de un desorden destructivo" -como nos recuerda, retomando a Norbert Elias, el último Eric Wolf (2001, p. 19-20). Sostengo que estas tres características podemos trasladarlas al complejo terreno de las "creencias" religiosas: es decir, remarcar el carácter segmentario, correlativo e interdependiente de las mismas. Como advierte Semán en su trabajo, es necesario seguir problematizando esta categoría naturalizada y normativizada en buena parte de nuestro discurso académico. De por sí, su discusión implicó una corriente de debate en la antropología desde los años setenta, cuando varios investigadores emprendieron una potente deconstrucción crítica de la misma, dilucidando la genealogía cristiana que la instiga, el dualismo genérico que la recorre ("creer en" - "creer que"), su inconsistencia constitutiva y la dificultad de traducirla a contextos culturales ajenos al estrecho mundo de la cultura burguesa y cristiana euroamericana (Needham, 1972; Asad, 1993; Ruel, 1997; Robbins, 2007). Uno de estos representantes, la reconocida etnógrafa de la brujería contemporánea en el occidente francés, Jeanne Favret-Sadda, volvió hace poco a remarcarnos la dificultad analítica que encierra la plurivocalidad de la noción de "creencia" y la necesidad de distinguir cómo en el lenguaje corriente se expresan tres facetas distintas: "1) el contenido proposicional de la creencia del sujeto, 2) la gama de posibles actitudes hacia este contenido, y 3) un tema determinado de apego a una actitud determinada (la consistencia es sorprendentemente poco común.)" (2012, p.46). En este sentido, cuando Ludueña nos impele a no subestimar "la reflexividad que, indefectiblemente, los actores desarrollan en el curso de la vida social" lo interpreto como una exhortación a estar alertas a dicha errática polisemia de la creencia, a su carácter indeterminado, flexible y situacional. 
La lectura comparada de los trabajos del debate me encaminó a conjeturar una pauta valorativa que conecta tanto la diversidad inherente al catolicismo argentino en su longue durée y actualidad como a las diferentes expresiones "religiosas" que lo sitúan y disputan con todas sus contradicciones, matices y fisuras propias. Parafraseando a Borges, llamaré a este patrón de características axiológicas: "nuestro rico individualismo religioso". Efectivamente, sea la vocación apóstata o autonómica respecto a las jerarquías de aquellas "ovejas negras" coloniales o republicanas (Di Stefano), o los movimientos católicos juveniles de entreguerras y su "notable independencia con respecto de la jerarquía" (Lida), o la "voluntad de diferenciación" de varias comunidades contemporáneas como grupos carismáticos o focolares con su representativa "carga de protesta" (Giménez Béliveau), nos inducen un sugestivo camino para la comparación. No hay dudas, desde ya, que toda dinámica religiosa se expresa en una arena de solidaridades y conflictos, de faccionalismos y heterodoxias, de presiones sociales y liberaciones personales. Ahora bien, el desafío es pensar en qué medida este valor, que oscila entre el deseo de independencia y el desacato, adquiere formas específicas en la dinámica histórica, institucional y cotidiana de nuestra "cultura religiosa", si es que podemos aventurar algo medianamente sensato sobre la misma sin caer en las esencialistas búsquedas de un perenne carácter nacional.

Cerraré esta segunda presentación retomando brevemente algunos señalamientos introducidos en la primera comunicación, donde busqué introducir en el debate la pregunta por los sentidos y usos que atraviesan la noción de "espiritualidad" y sus relaciones con la de "religión". Me interesa sugerir para futuros estudios la necesidad de entender las raíces históricas y las configuraciones contemporáneas que habilitan pensar sobre algunos de los sentidos y prácticas que envuelven al término "espiritual" en el discurso público local. A partir de la lectura de los trabajos presentados, considero que la significación social de esta vocación de desacato y autonomía que atraviesa como 'discurso oculto' -en el sentido de James Scott- parte de la historia y actualidad de las religiones en Argentina puede ser puesta en correlación con la naturalizada noción de "espiritualidad". El uso de esta categoría por los agentes se presenta como distinta, ora opuesta, ora complementaria, a aquella de "religión", donde se remarcan las cualidades dogmáticas de esta última y su inherente voluntad de poder. Si bien este "sentido común masivo" -en las ya citadas palabras de Semán- está inserto en una trama global donde las proclamas de autoctonía, autonomía y crecimiento permean la 'efervescencia espiritual' en diversos países, y donde reconocidos estudiosos piensan (al igual que los sujetos que estudian) que debe emanciparse de la categoría "religión" (Hellas, 2008), el reto es tratar de comprender las articulaciones locales del mismo. De esta manera, y avizorando futuras indagaciones, considero necesario preguntarse sobre los sentidos asociados a las "creencias" (en un dios personal, en una energía cósmica, en el potencial individual, etc.) y sus relaciones con las "prácticas" espirituales (como la meditación, la escucha y la lectura, el trabajo corporal, etc.), para repensar así las continuidades y rupturas que estas presentan con los valores asociados a la religión, la diversidad y el pluralismo en la sociedad argentina contemporánea.

\section{Pablo Semán}

I- Un tema transversal al de la discusión sobre la "Argentina Católica" es el de la necesidad de redefinir el término "religión". Redefinición que emerge como necesaria si 
se consideran tanto las transformaciones sociales contemporáneas como las mutaciones de la mirada de los cientistas sociales sobre lo religioso que no sólo se aplican a la actualidad sino, también, de forma retrospectiva al pasado. La mencionada redefinición se retroalimenta de la crisis que ella misma le plantea a dos supuestos implicados en el término religión: la naturalización de la autonomía de lo religioso y la naturalización de su referencia a las ideas de alma y de trascendencia que dependen de la hegemonía que tuvieron ciertas perspectivas cristianas para definir el contenido "supuestamente eterno" del "campo religioso" (la postulación de lo sagrado como algo que se encuentra más allá, y la definición del bienestar espiritual en base a una problemática del "alma", algo que era diferente del cuerpo y la mente). El contenido positivo de esa redefinición no puede ser otro que el de entender que "campo religioso" es una convención estrecha y resulta subvertida en una dirección: el campo religioso es menos un campo de disputas interinstitucionales por la primacía en la "cura de almas" y el saber del "más allá", que un entramado de producción conflictiva y policéntrica de nociones de reparación, de mejora y de bien en el que lo que se disputa es, justamente, cuáles son y cómo se articulan los sujetos y las dimensiones de lo que se repara, mejora, cura, salva o perfecciona. La especificidad de lo que llamábamos "religioso" está dada por un hecho: que sean cuales sean los códigos que se aplican para definir lo "religioso" está implicado un nivel de construcción de la persona que, para no identificar la definición con una posición determinada en el campo "religioso", puede entenderse como "hiperrelacional" (e implica sujetos, niveles, eventos más amplios, más fuertes, mas importantes que los de los humanos). Pero hay algo más: si los trabajos de Cernadas, Frigerio, Giménez Béliveau, Ludueña y Semán apuntan esa cuestión en la sincronía contemporánea los trabajos de Di Stefano y Lida ofrecen la posibilidad de pensar cuanto se ganaría con la percepción realista (heterogeneizada y tensional) de lo que resulta obturado por la noción monolítica de "nación católica". Así, la desnaturalización de la religión que alentamos no sólo se refiere al presente aun cuando este presente muestre, respecto del pasado, ciertas discontinuidades. Inversamente, y calibrando nuestra afirmación inicial, no es necesario suponer que sólo estas discontinuidades contemporáneas, obligan a redefinir lo religioso: los trabajos de los historiadores también nos muestran que la concepción del campo religioso como campo de competencia entre formulaciones opuestas de la cura de almas es una definición que oscurecía otras religiosidades y se identificaba con las de algunos actores que, no por ser dominantes, eran absolutamente dominantes urbi et orbi y por todos los tiempos. Es necesario revisar hasta qué punto esa visión no depende de la mirada dominante de los analistas, mas agobiada de catolicismo que la propia sociedad. Ahora bien: de la misma manera que los hechos de la nación católica (y no sólo ellos sino también la manera de identificar religiosidad con la institución, por ejemplo) son magnificados por el "catolicocentrismo" de las ciencias sociales de la religión, debe interrogarse en qué grado nuestras actuales ideologías de época influyen en nuestra percepción del "campo religioso". No para rechazar las innovaciones conceptuales, pero si para no detener los efectos de aprendizaje del proceso reflexivo. Sería interesante discutir en qué grado y de que forma el pluralismo democrático, el liberalismo y la espiritualidad de la nueva era, solo por nombrar algunos factores, acompañan nuestros intereses, nuestros énfasis y nuestras percepciones para que el relevo crítico del catolicocentrismo no sea una ingenua proyección alineada con "otra religiosidad" sino la oportunidad de poner en perspectiva "lo religioso" 
II- En este contexto un tema que depende de los dos anteriores es el de las dinámicas de institucionalización de la religión. Los trabajos de Ceriani, Frigerio, Gimenez Béliveau y Ludueña apuntan a esta cuestión a la que también lo hizo mi propio trabajo. Hay un argumento que corre el riesgo de generar una circularidad improductiva. Que la religión o la espiritualidad no tomen formatos católicos, no se organicen con aspiración a la duración y a cierto "sedentarismo" no quiere decir que hayan desaparecido las instituciones. Cambio de formato no es desinstitucionalización. En ese sentido vale la pena recordar el argumento de Durkheim en las Lecciones de Sociología: el individualismo (correlativo de la supuesta desinstitucionalización) es en sí mismo una institución. La noción de desinstitucionalización oscurece fenómenos de orden muy diferente que se conjugan en ese rótulo. En primer lugar oculta el ya citado problema de la identificación de un formato particular con un formato universal. En segundo lugar oculta que institución es no sólo sustantivo sino también verbo. La institución es, siempre, un dinamismo entre lo instituido y lo instituyente por lo que el cambio y la fluidez son parte de su definición. El cambio de escalas en que ocurre la institucionalización atañe a los grupos y a los tiempos. Pero el hecho de que la espiritualidad se desarrolle en "instituciones lábiles", en grupos pequeños y evanescentes, que conviven con otras opciones, incluso las prácticas solitarias, no implica "desinstitucionalización". Si se atiende a las dos especificaciones hemos realizado en este punto. Desinstitucionalización implica una categorización meramente negativa que incurre en un cierto absurdo: como ir a la luna y describirla por la ausencia de shoppings. En tercer lugar hay que rescatar algo ontológicamente positivo bajo el término desinstitucionalización. Esto implica desplegar otro tema: el del incremento de la agencia de los sujetos y el cambio en las relaciones con la verdad.

III- Sea porque apuntamos a otra dimensión, sea porque esta dimensión se ha transformado o hecho más visible, lo cierto es que las ciencias sociales de la religión han enfatizado el momento del actor, el sujeto, la agencia. En ese sentido las reapropiaciones, las producciones individuales ganan realce y de cierta forma compiten o desestructuran el momento de la institucionalización. Lo expuesto en base al argumento durkheminiano nos permitiría salir de la falsa identificación entre institución=colectivo vs. desinstitucionalización=individualidad. Pero más allá de que la individualidad sea una institución es posible apuntar algo. Es necesario preguntarse si el énfasis contemporáneo en el sujeto, la importancia correctamente atribuida a la agentividad no es el hilo que debe seguirse para entender que el cambio que se entiende mal con el rótulo de "desinstitucionalización" se entiende mejor tomando conciencia de que el hecho es la tensión entre sujetos e institución y que la llamada desinstitucionalización es en algún caso la producción de formas de subjetividad que deben ser descriptas en su singularidad, en su recurrencia, en las lógicas que asisten a su multiplicación. En ese contexto, volviendo al inicio, se entiende que nuestras preocupaciones actuales necesariamente deban referirse al hecho de que la "religión se sale de lugar" e incluye otras prácticas (que no solo las del alma y el espíritu): la llamada desinstitucionalización tiene que ver con que la religión no se queda quieta: ni en el lugar donde la puso la modernidad -como dominio autonómo y confinado-, ni en las prácticas de los sujetos -que no la construyen como dimensión exclusivamente relativa al alma o, incluso, resisten esta categoría-. Por último, una cuestión que solo quiero indicar y que creo que debe ser objeto de una indagación ulterior, muchísimo más dilatada en lo teórico y lo empírico: mucho de lo que emerge con la pluralización y con el reconocimiento de la pluralización de lo espiritual y lo religioso 
habla de un cambio cultural muchísimo más importante. Sin que esto forme parte de una tendencia lineal e irreductible parece ser que, al menos nuestras sociedades, en parte, se asientan cada vez más sobre "la libre interpretación de los textos".

IV- Estos cambios que son al mismo tiempo culturales y de las disciplinas orientadas a la cultura deben relacionarse con los cambios de escala de nuestras sociedades. No solo me refiero a que nuestra demografía es escasamente seguida de cerca por las instituciones tradicionales y a que eso genera otras posibilidades de cambio. También al hecho de que las trayectorias vitales se han hecho al mismo tiempo más variadas y extendidas. En ese sentido es necesario entender que "la religión" o "las nuevas formas de espiritualidad", con medios que no son la capilla y el sacerdote, operan en relación con campos que antes no lo hacían: si las nuevas espiritualidades se nutren de psicología, también hay que ver que los nuevos creyentes utilizan esa espiritualidad para generar opciones en su propias instituciones y campos de acción: allí donde los reglamentos o las expectativas tradicionales no funcionan, las ideas de la nueva era ponen su cuota de directividad. De directoras de escuela que reorganizan el funcionamiento del colegio basadas en literatura espiritual contemporánea a políticos que incorporan y naturalizan el lenguaje de la nueva era, pasando por cientistas sociales que, todavía a hurtadillas, se disocian entre su vida cotidiana y el lenguaje científico de rigor. En la estructura social contemporánea la religión se sale de su lugar y retorna, con otros fueros, por otros espacios.

\section{Verónica Giménez Béliveau}

Probablemente uno de los mayores desafíos que plantea el estudio del catolicismo desde las ciencias sociales tenga que ver con la perspectiva, más que con las distintas facetas del objeto en sí. Pensar el catolicismo actual como un espacio plural, abierto a distintos discursos e influencias, permeable, definitivamente heterogéneo y alejado de concepciones monolíticas y cerradas del mismo, atravesado por corrientes variadas, en cuyos distintos espacios y en sus límites se mezclan sociabilidades y representaciones provenientes de otros grupos religiosos, espirituales y sociales, requiere de un ejercicio de descentramiento institucional de la mirada. Estudiar al catolicismo desde la mirada fija en la institución representa un sesgo que no permite comprender la dinámica de las creencias en el mundo actual, no sólo porque enfoca el núcleo de una vasta dinámica cuyas diversas periferias quedan entonces en la penumbra, sino también porque puede llevar a suponer una transmisión automática de preceptos, valores y prácticas que sólo son un proyecto de las jerarquías de la Iglesia. Un programa de investigación sobre el catolicismo debería no sólo enfocar la institucionalidad, la Iglesia y sus relaciones con el Estado y la política, sino también lo que los católicos hacen con esa institucionalidad: no se trata de quitar a la institución de nuestras reflexiones, sino de tomarla como un elemento más en el armado de espacios de sociabilidad, nudos de presión e influencia, construcción de identidades. Para ello, me parece útil pensar el catolicismo desde tres conceptos: diversidad, autonomía y mixtura, o sincretismo

1. Pensar la diversidad. En el primer artículo que escribí en este debate sostenía la pluralidad actual del catolicismo, enfocando particularmente dos lógicas distintas de sociabilidad, las comunidades y los católicos desafiliados. Estos dos espacios, que construyen formas diversas de ser católico, no son los únicos, y exponen un amplio abanico de opciones teológicas, doctrinarias, militantes, practicantes y no practicantes que el catolicismo actual muestra. 

se enraíza profundamente en la historia argentina, aunque fue opacada por el discurso de la utopía de la nación católica, una narrativa que, como la describe Frigerio (2002 y en este debate), se pretende "blanca, europea, moderna, racional y católica", y, sobre todo, homogénea y unívoca en su constitución y proyecto político.

Sin embargo, a lo largo de los últimos 30 años de democracia, asistimos al descentramiento del "mito de la nación católica" (Lida, en este debate), lo que permite incluso a los agentes de las jerarquías eclesiásticas tomar a la diversidad como un dato, y repensar su puesta en práctica en circunstancias socio-políticas determinadas. La reflexión sobre un acontecimiento que viabilizó la intervención de la Iglesia en el espacio público nos permite ver este proceso con claridad. Durante la discusión de la Ley de Matrimonio Igualitario en el congreso de la nación, en el año 2010, la campaña en contra de la ley fue encabezada por dos diputadas ligadas orgánicamente a grupos confesionales: Liliana Negre de Alonso, al catolicismo, y Cynthia Hotton, al campo evangélico (Carbonelli, Mosqueira y Fellitti, 2011). Si comparamos este proceso con la intervención de la Iglesia en el momento de la sanción de la ley de divorcio, en 1987, vemos que en ese entonces la campaña fue encabezada por un prelado (el entonces obispo de la diócesis de Mercedes-Luján, Emilio Ogñenovich), y sostenida por varios obispos, que le "pusieron el cuerpo" a la acción antidivorcista (Fabris, 2008). Comparando los dos momentos y la manera en que se produjeron los acontecimientos y las intervenciones de los grupos, es posible identificar dos tendencias que marcan la puesta en práctica de un diálogo, yo diría inédito, del catolicismo argentino con la diversidad. La primera es hacia el interior del campo católico, y tiene que ver con el desplazamiento de los obispos de un lugar de centralidad escénica a un segundo plano, y la aparición de un nuevo actor dentro de la Iglesia, los especialistas profesionalizados, que ocupan un lugar medular en las discusiones públicas, marcando la voz de la Iglesia. Éstos son juristas, políticos, médicos, psiquiatras, bioeticistas formados en universidades de primer nivel, reconocidos especialistas en sus disciplinas, que encarnan la perspectiva de la institución desde un lugar renovado (Irrazábal, 2012). La segunda tiene que ver con el reconocimiento por parte de la Iglesia de la presencia de otros actores religiosos en el campo de la palabra pública: el armado de la campaña en contra del matrimonio igualitario se articuló sobre la alianza entre una diputada católica y otra evangélica, y mostró en los hechos la constitución de un espacio interconfesional para sostener un proyecto político concreto (Carbonelli e Irrazábal, 2010). Como vemos, incluso en los espacios de decisión de la Iglesia católica argentina, la misma que eligió históricamente identificarse con la nación, se dan procesos de admisión de la diversidad interna y externa.

2. Pensar la autonomía. Así como pensar el monopolio desde la extensión completa del catolicismo en la sociedad forma parte del relato de la utopía del catolicismo integral, pensar la hegemonía desde la transmisión fiel de doctrinas, contenidos y sociabilidades desde las jerarquías hacia las bases y de una generación a otra también forma parte del mismo esquema. Toda una serie de representaciones asociadas, como el postulado de que las posiciones morales de las jerarquías van a ser asumidas y actuadas por las personas por el sólo hecho de definirse católicas forma parte de un discurso que sostiene el proyecto político y performativo de la Iglesia para la sociedad.

La autonomía de los católicos respecto de las autoridades eclesiásticas no es un dato nuevo. Roberto Di Stefano (1998) destaca ya en la época colonial la dificultad de los obispos para contar con un clero obediente y alineado con las políticas que las jerarquías

Corpus, Vol 3, No 2 | 2013 
episcopales. Cuando estudiamos la evolución de la población desde el punto de vista demográfico notamos que en Argentina la "transición demográfica", es decir el proceso de control de la natalidad por parte de la población, que pasa de tener un promedio de siete hijos a un promedio de tres, se produce en Argentina temprana y rápidamente (Torrado, 2007): hacia los años 1920/ 1930 estaba ya concluido. Es decir que, más allá de las prédicas sistemáticas y constantes de la Iglesia (e incluso en algunos períodos del estado nacional), y de las corporaciones médicas, las mujeres y las parejas controlan efectivamente la cantidad de hijos que deciden tener, recurriendo a métodos anticonceptivos eficaces (Torrado, 2007).

50 A principios del siglo XXI la distancia que las personas establecen con los postulados de la Iglesia en las cuestiones relacionadas con la regulación familiar son evidentes. Un estudio de 2008 (Mallimaci, 2013) muestra que la mayoría de la población residente en Argentina considera que se pueden utilizar anticonceptivos y seguir siendo un buen creyente (y la mayoría de las católicas y católicos en edad fértil efectivamente los usan), está a favor de que la escuela incorpore cursos de educación sexual para los alumnos e informe acerca de los métodos anticonceptivos, está de acuerdo con que hospitales, clínicas y centros de salud ofrezcan métodos anticonceptivos de manera gratuita, y considera que las relaciones sexuales antes del matrimonio son una experiencia positiva.

51 La idea de autonomía nos permite pensar la marca de la época en todos los procesos sociales, incluido el espacio del catolicismo: resulta útil aquí parafrasear el proceso de autonomía del individuo y usarlo para pensar la autonomía del creyente católico como una marca de la sociedad argentina de la modernidad tardía. Y en este sentido, siguiendo un programa de investigación que estudie el catolicismo desde una perspectiva no catolicocéntrica, sería interesante comparar las autonomías relativas de fieles de diferentes confesiones. Al fin y al cabo, siguiendo el razonamiento de Maurice Halbwachs (2004, p. 231), "Ciertas consideraciones permiten pensar que un católico, diez o quince siglos más tarde, comprenderá mucho menos los evangelios que un pagano o que un judío, que un oriental o un romano de los primeros siglos después de Cristo, la forma de vida social que se supone vivieron y en la que nacieron los primeros cristianos".

3. Pensar las mixturas y los sincretismos. Vimos que la noción de autonomía nos servía para pensar el estado actual del catolicismo: los católicos son autónomos respecto de los mandatos institucionales, e incluso respecto de los contenidos de práctica y culto transmitidos desde las generaciones anteriores. Pero para completar una reflexión sobre cómo abordar el análisis del catolicismo en Argentina debemos profundizar también en otras categorías que cuestionan, nuevamente, la idea de monopolio: las mixturas y los sincretismos. La idea de monopolio/hegemonía supone una suerte de espacio social estanco, cerrado a influencias y corrientes varias. $Y$ lo que nuestros trabajos de campo nos muestran hoy es un constante recurso de los católicos y católicas a distintos elementos, discursos y universos simbólicos originados fuera del catolicismo. No sólo podemos constatar estas interacciones constantes, sino que debemos asumir la complejidad de estas interacciones. Como sostiene Ceriani en este volumen, las prácticas cotidianas en distintos espacios de actividad dan cuenta de una mezcla no sólo entre tradiciones religiosas, sino también de flujos y desplazamientos entre distintos campos de acción, como el recurso a técnicas espirituales en el tratamiento de enfermedades varias en centros de salud, o las consultas sistemáticas a psiquiatras por parte de sacerdotes exorcistas en casos de personas que se piensan poseídas por el demonio. La organización de la vida de las personas se desarrolla alrededor de diversos ejes, que conviven con dosis 
de conflicto en general bajas. Los momentos en que el trabajo de alguien se ve afectado por sus convicciones religiosas, o cuando la resolución de un problema de salud entra en conflicto con preceptos éticos son contados, y la mayoría de las veces las diferentes espacios de sociabilidad e identificación se articulan de manera relativamente fácil, y en función de las conveniencias, identidades y lugares sociales de los que las personas son portadoras.

Diversidad, autonomía, mixturas y sincretismos me parecen tres conceptos centrales para emprender una reflexión sobre el catolicismo actual desde una perspectiva que no coloque a la institución en el centro del catolicismo, ni al catolicismo en el centro de la sociedad. Esto supone buscar, como invita Semán en su artículo en este volumen, lo heterogéneo, lo plural, lo móvil dentro de los fenómenos que estudiamos, y enfocar el catolicismo como un locus articulado en torno de una serie de continuidades y transformaciones, abierto a influencias y atravesado por tensiones.

\section{Alejandro Frigerio y Gustavo Ludueña - Reflexiones finales de los editores del dossier}

54 La dinámica de trabajo para este dossier consistió en dos momentos diferenciados de producción. En la primera buscamos estimular la reflexión individual sobre los ejes que sugerimos para el debate, tal como los expusimos en la introducción, para la escritura de una primera tanda de artículos. En una instancia posterior, se intercambiaron entre los autores para la escritura de una segunda ronda de textos que debatieran visiones, posiciones o, directamente, enunciados de los otros, con los que entablar un intercambio de perspectivas críticas a partir de los temas propuestos. Pese a las diferencias en proveniencia académica y disciplinar, y las diversas líneas argumentativas expuestas, hubo un consenso respecto del valor positivo de la diversidad religiosa, de su estudio y de la introducción de nuevas perspectivas y, por otro lado, acerca de la imposibilidad real de sostener la existencia de un monopolio católico -pasado o presente- dado el estado actual de nuestro saber sobre las religiones en Argentina.

Las apropiaciones particulares de cada invitado en la selección del tema fue en general heterogénea. A la variedad inicial surgida de las adscripciones disciplinares de cada autor, un verdadero hándicap impuesto ad hoc contra la homogeneidad que quisimos eludir, se sumaron las maneras en las que se sintieron interpelados por la propuesta. La combinatoria de ambas mostró diferencias, por un lado, en cuanto a la construcción literaria y analítica de los escritos en la definición y abordaje de cada problema planteado en torno a la convocatoria como, por otro lado, en los intereses concretos que ocuparon los análisis de cada artículo. Con relación a este último aspecto, los tópicos que cautivaron la atención pueden inscribirse en dos grandes núcleos: primero, las consecuencias epistemológicas que conlleva el abordaje sobre la diversidad desde los estudios sociales de la religión en el marco de las tradiciones académicas existentes (Frigerio, Semán, Ceriani Cernadas y Ludueña) y, en segundo lugar, los procesos históricos en la longue durée (Di Stefano y Lida) y los sociológicos de tono sincrónico que se asocian a la diferencia religiosa (Giménez Béliveau).

En general, los escritos parecieron eludir la confrontación directa de las opiniones de los otros, profundizando más bien las líneas de pensamiento que ya habían presentado en sus primeras versiones. Las lógicas textuales privilegiaron el camino del diálogo a través de la 
citación de los otros participantes y de sus ideas en los escritos variando en grados diferenciales de inclusión. En este sentido, se pudieron notar desde sutiles diálogos de silencio que parecieron no querer dirimir tópicos puntuales de manera directa sobre los que podían exhibir desacuerdos hasta inclusiones reales más consistentes que dieron lugar a desarrollos más finos para elucidar aciertos, convergencias o divergencias. El resultado es, de todas maneras, rico en definiciones y visiones de la agenda futura de los estudios de la religión. De forma global, el debate mostró una crítica unánime a la idea de monopolio religioso católico y un fuerte cuestionamiento a otros conceptos a ella asociados como los de desinstitucionalización y autonomía de la creencia, así como una conversación inexorable y reconocidamente postergada con la historia, sea explícita o implícita, para quienes no venimos de ese espacio académico.

La diversidad, más que otros polos de discusión, se mostró como protagonista estelar y, de forma concomitante, en tanto problema de estudio presentó los asedios de una doble barrera. Por un lado, las tradiciones epistémicas de la academia (y de cada disciplina en especial) que condicionan desde los esquemas conceptuales y teóricos una llegada versátil y menos sesgada al problema de la diversidad religiosa; aquí la historia se separó presentando una dificultad más metodológica que conceptual basada en la falta de fuentes primarias para los estudios de caso sobre determinadas aristas. Por otro lado, de modo similar, están las limitaciones fácticas inmediatas en cuanto a la existencia y trayectoria de estudios empíricos que proporcionen una acumulación crítica de material como para discutir y problematizar el lugar social, histórico y cultural de las diferentes expresiones religiosas en Argentina. Asimismo, hubo tópicos que aun siendo menos generales no dejaron de ser transversales a su medida y ocuparon, igualmente, varias de las líneas de este intercambio. Entre ellos podemos mencionar, por ejemplo, las nociones de monopolio, religión e institución.

En el caso del proclamado monopolio católico, por ejemplo, y en sintonía con las apreciaciones críticas ya expuestas por Frigerio (2007), el debate canalizó otras voces que convergieron con esa misma perspectiva. Así, Di Stefano afirma que esa idea "es inadecuada, incluso en referencia con los períodos en los que su vigencia ha sido menos cuestionada por parte de los historiadores". Por su parte, Giménez Béliveau propone un uso restringido de ese supuesto monopolio católico que únicamente podría "ser pensado como un horizonte utópico institucional". En una línea epistemológica más laxa, Ludueña lo visualiza como parte de un paradigma más genérico aliado a un conglomerado de axiomas teóricos y empíricos que aun visto al interior del ordo católico resulta "frágil", y de mucha más dudosa solidez todavía hacia el exterior. En suma, la idea de monopolio religioso -y "católico" en particular-, si bien epistemológica y conceptualmente atada a una perspectiva teórica sociológica específica, parece haberse hecho cómplice del mito de la nación católica logrando -podría afirmarse- una suerte de academización de su eficacia en la percepción global de lo que varios de los autores de este debate entienden (no sin cada vez más serios reparos conceptuales) como campo religioso.

Si bien el catolicismo logró éxito cultural al permear silencioso en los esquemas interpretativos de los argentinos, no excluyó a los académicos quienes no necesariamente debieron llegar a ejercer una práctica confesional de sus disciplinas, como sí sucedió en los estudios iniciales de la religión por parte de la historia y de la sociología, para sobreestimar el rol real de esa denominación religiosa en la sociedad $\mathrm{y}$, concomitantemente, en el análisis social. Este vínculo con la academia es especialmente destacado por Frigerio, al señalar la responsabilidad de las producciones disciplinares en 
asumir una "hegemonía católica" que, vía tanto del monopolio como de una tácitamente aceptada eficacia simbólica estadística reflejada principalmente en la identificación nominal de los sujetos, manifiesta efectos colaterales para la diversidad religiosa que se traducen en su sistemática invisibilización (o, en la mejor de las situaciones, su minimización como presencia atendible en nuestro país).

Por otro lado, el concepto de religión vuelve a ser objeto de revisión en función de lo que la academia percibe como un renovado paisaje sobre el que se dibujan las expectativas religiosas de las personas que nos ofrece la sociedad contemporánea (Ceriani, Semán). En este sentido, existe casi un común acuerdo en las dificultades que el mismo genera tanto para la comprensión del catolicismo, como para todas las demás expresiones que convocan las voluntades cosmológicas de los argentinos. En idéntica frecuencia está la noción de desinstitucionalización con la que suele alinearse el monopolio, la cual derivó en este debate en una revalorización de las relaciones sociales respecto de la formación de nuevos tejidos, redes y entramados (Frigerio, Semán, Ludueña), los que en paralelo obligan a una revisión de la idea de institución con la que se ha venido trabajando en el marco de lo que Semán denomina "perspectivas institucionalistas de la religión". En oposición a estos enfoques, consistente resulta la aserción de Ceriani acerca de que ya "[n]o hay dudas [...] que toda dinámica religiosa se expresa en una arena de solidaridades y conflictos, de faccionalismos y heterodoxias, de presiones sociales y liberaciones personales". Expresión que, en adición a su precisión fáctica, sitúa en un lugar de inmovilidad analítica a los enfoques caracterizados por una mirada cosificada y estática de la institución. Quien destacó también esta reificación fue Frigerio en su observación, vía Brubaker (2002), en torno del "grupismo"; un principio epistémico según el cual, asevera el autor, se acepta que "efectivamente existen 'grupos' en-el-mundo-allí-afuera".

Por último, aunque no menos significativo, el tratamiento de la diversidad evidenció igualmente la importancia del estudio -o al menos de la discusión necesaria hasta ahora no valorizada- en torno a la(s) cultura(s) religiosa(s) existentes en nuestro país. En este terreno, siendo que las trayectorias en estudios sociales sobre las religiosidades urbanas provienen más de la historia y de la sociología que de la antropología (la que incursionó más tardíamente en esta esfera), las perspectivas sobre cultura y religión se presentan ahora para esta última disciplina como un horizonte sustantivamente promisorio.

\section{BIBLIOGRAFÍA}

Asad, T. (1993). Genealogies of Religion Discipline and Reasons of Power in Christianity and Islam. Baltimore: John Hopkins University Press

Brubaker, R. (2002) Ethnicity without groups. European Journal of Sociology, 43, 163-189.

Caimari, L. (1994). Perón y la Iglesia católica. Religión, Estado y sociedad en la Argentina 1943-1955. Buenos Aires: Ariel. 
Carbonelli, M., Irrazábal, G. (2010) Católicos y evangélicos. ¿Alianzas religiosas en el campo de la bioética argentina?, Nómadas. Revista Crítica de Ciencias Sociales y Jurídicas, 26 (disponible online en http://pendientedemigracion.ucm.es/info/nomadas/26/carbonelli_irrazabal.pdf).

Carbonelli, M., Mosqueira, M. y Felitti, K. (2011). Religión, sexualidad y política en la Argentina: intervenciones católicas y evangélicas entorno al aborto y el matrimonio igualitario, Revista del Centro de Investigación Universidad La Salle, 9 (36), 25-43.

Carozzi, M.J. (2000). Nueva Era y terapias alternativas. Buenos Aires: EDUCA.

Ceriani, C. (2013). La religión como categoría social: encrucijadas semánticas y pragmáticas. Cultura y Religión, 7 (1), 10-29.

Cohen, R. (1985). El sistema político. En Llobera J. (comp.), Antropología Política. (pp. 27-53). Madrid: Anagrama.

Di Stefano, R. (1998) Abundancia de clérigos, escasez de párrocos: las contradicciones del reclutamiento del clero secular en el Río de la Plata (1770- 1840), Boletín del Instituto de Historia Argentina "Dr. E. Ravignani", 16-17, 33-59.

Fabris, M. (2008) La Iglesia Católica y el Retorno Democrático. Un Análisis del Conflicto PolíticoEclesiástico en Relación a la Sanción del Divorcio Vincular en Argentina, Coletâneas do nosso tempo, año VII, 8, 31-53.

Fabris, M. (2011) La Conferencia Episcopal en tiempos de retorno democrático, 1983-1989. La participación política del actor eclesiástico. Tesis doctoral. Universidad Nacional de Mar del Plata.

Favret-Saada, J. (2012). Death at your heels When ethnographic writing propagates the force of witchcraft, HAU: Journal of Ethnographic Theory, 2 (1), 45-53.

Frigerio, A. (2000). Teorías económicas aplicadas al estudio de la religión: ¿Hacia un nuevo paradigma? Lecturas Sociales y Económicas 34, 34-50.

Frigerio, A. (2002) Outside the nation, outside the diaspora: Accomodating race and religion in Argentina, Sociology of Religion, 63(3), 291-315.

Frigerio, A. (2007). Repensando el monopolio religioso del catolicismo en la Argentina. En M. Carozzi y C. Ceriani (Comps.), Ciencias sociales y religión en América Latina (pp.87-118). Buenos Aires: Biblos/ACSRM.

Frigerio, A. (2013). (Des)Centrando el concepto de religión. Blog DIVERSA, Red de Estudio de la Diversidad Religiosa en Argentina. Disponible: http://www.diversidadreligiosa.com.ar/blog/?p=599

Frigerio, A. y Wynarczyk, H. (2013). La diversidad religiosa en Argentina: Un desafío a la ciencia normal. Religión y Cultura, 7 (1), 3-9.

Halbwachs, M. (2004) Los marcos sociales de la memoria. Barcelona: Anthropos.

Hellas, P. (2008). Spiritualities of Life. New Age Romanticism and Consumptive Capitalism. Oxford: Blackwell.

Irrazábal, G. (2012) Bioeticistas católicos en contra de las técnicas de reproducción asistida. Implicancias para la futura Reforma del Código Civil Argentino, Revista Derecho de Familia, 57, 113-134.

Lida, M. (2010) Catolicismo y peronismo: la zona gris, Boletín Ecos de la Historia, Universidad Católica Argentina, 6.

Lida, M. (2012) Catolicismo y sensibilidad antiburguesa. La Iglesia Católica en una era de desarrollo, 1955-65. Quinto Sol, 16 (2), 157-176. 
Lida, M. (2013). Monseñor Miguel De Andrea. Obispo y hombre de mundo. Buenos Aires: Edhasa.

Lida, M. y Fabris, M. (2013). Argentina and the Pope of the End of the World: Antecedents and Consequences. Journal of Latin American Cultural Studies, 22 (2), 113-121.

Ludueña, G. (2009). La cultura católica en la imaginación política de las iglesias latinoamericanas. En C. Steil, E. Martín y M. Camurça (Eds.), Religiones y Culturas. Perspectivas Latinoamericanas (pp. 115-154). Buenos Aires: Biblos

Ludueña, G. (2013). Por una epistemología relacional de los fenómenos religiosos. Blog DIVERSA, Red de Estudio de la Diversidad Religiosa en Argentina. Disponible:

http://www.diversidadreligiosa.com.ar/blog/?p=790

Mallimaci, F. (director) (2013). Atlas de las creencias religiosas en Argentina. Buenos Aires: Biblos.

Martín, J. P. (1992) El Movimiento de Sacerdotes para el Tercer Mundo. Un debate argentino. Buenos Aires: Guadalupe.

Needham, R. (1972). Belief, language and experience. Oxford: Basil Blackwell.

Robbins, J. (2007) Continuity thinking and the problem of Christian culture. Belief, time and the anthropology of Christianity, Current Anthropology, 48(1), 5-17.

Ruel, M. (1997). Belief, Ritual and the Securing of Life: Reflexive Essays on a Bantu Religion. Leiden: E. J. Brill.

Semán, P. (2013). Pentecostalismo, política, elecciones y poder social. Religión y Cultura, 7 (1), 60-81.

Torrado, S. (2007). Transición de la fecundidad. Los hijos ¿cuántos? ¿Cuándo?, en Torrado, S. (comp.), Población y Bienestar en Argentina del Primero al Segundo Centenario. Una historia social del siglo XX, Tomo I. Buenos Aires: Editorial EDHASA.

Touris, C. (2008) Sociabilidad e identidad político-religiosa de los grupos católicos tercermundistas en la Argentina (1966-1976). En Moreyra, B. y Mallo, S. (eds.), Miradas sobre la historia social argentina en los comienzos del siglo XXI. (763-783) Córdoba: Centro de Estudios Segretti. Wolf, E. (2004). Figurar el Poder. Ideologías de dominación y crisis. México: CIESAS.

Zanatta, L. (1996) Del Estado liberal a la nación católica. Iglesia y Ejército en los orígenes del peronismo. Buenos Aires: UNQ.

Zanca, J. (2013). Cristianos antifascistas. Conflictos en la cultura católica argentina. Buenos Aires: Siglo XXI.

\section{NOTAS}

1. La frase remeda el "sicut erat in principio et nunc et semper et in saecula saeculorum" del Gloria. 